To dissociate lysines's own effect from that of the total protein supply, two trials have been carried out on finishing pigs (between 60 and $90 \mathrm{~kg}$ live weight) to study the supplementation of a maize diet with either soya-bean oil meal alone, or combined with a low-quality protein source, poor in lysine (maize gluten or feather meal).

The results show that raising the crude protein content from $\mathrm{I} 5$ to $\mathrm{r} 8 \mathrm{p}$. Ioo in diets containing 0.7 p. Ioo lysine leads to improvement of the carcass quality in females, but not in castrated males. This effect is due to a supplementary supply of non-specific nitrogen, independent of the lysine level, after satisfying the requirement for this amino acid.

\title{
SUBSTITUTION A UN RÉGIME « MAÏS + SOJA ", SOIT DE MAÏS « RICHE EN LYSINE », SOIT DE LEVURES CULTIVÉES SUR ALCANES ET DE TOURTEAU DE COLZA FERMENTÉ; ESSAI SUR « LARGE WHITE » ET SUR « HYPOR "
}

\author{
A. GAYE et J. MOAL \\ Association générale des Producteurs de Maïs, \\ 64 - Pau
}

RÉSUMÉ

Partant d'un régime " maïs + tourteau de soja cuit " à $\mathbf{1} 7,5$ p. Ioo de matières azotées brutes (MAB) et $0,96 \mathrm{p}$. Ioo de lysine, les auteurs essaient deux types de substitution, à niveau de lysine constant $(0,96)$ sur 16 porcs par régime, nourris semi ad libitum en loges individuelles de 25 à I03 $\mathrm{kg}$ de poids vif.

I. Emploi de maïs "riches en lysine" (sélections en cours de l'I. N. R. A. Clermont-Ferrand) et / ou de lysine de synthèse. Les performances d'élevages sont extrêmement voisines, mais les carcasses sont d'autant plus grasses que le taux de MAB décroît ( 7 7,5 à I $5, \mathrm{I})$. Les maïs riches en lysine semblent d'intêrêt limité (le maïs passe de $7 \mathrm{I}, 6$ à $75,8 \mathrm{p}$. Ioo du régime).

2. Emploi de levures d'alcanes (Sté BP) et de tourteau de colza fermenté. Un régime à 83,8 p. Ioo de mais et 13,2 p. Ioo de levures, assure les mêmes performances d'élevage que le témoin et des carcasses meilleures, bien que le pourcentage de MAB soit réduit à $I 6,2$. Dans le deuxième cas, la croissance est très ralentie $(634 \mathrm{~g} / \mathrm{jour}$ contre $76 \mathrm{r})$ et l'indice de consommation (IC) est très élevé $(3,88 \mathrm{~kg}$ contre 3,28$)$.

Tous régimes confondus, les "Hypor " ont consommé et crû moins que les Large White (IC équivalents) ; leurs carcasses étaient beaucoup plus belles, mais certains d'entre eux ont beaucoup souffert au cours de leur transport à l'abattoir.

Pas d'interaction régimes $x$ types de porcs. 


\title{
SUMMARY
}

\section{PROTEIN SUPPLEMENTATION OF MAIZE + SOYA-BEAN DIETS IN LARGE WHITE \\ AND HYPOR PIGS}

Using maize + cooked soya-bean diets containing 17.5 p. Ioo crude protein and 0.96 p. xoo lysine, two types of substitution were studied with $\mathrm{I} 6$ pigs per diet, fed semi ad libitum in individual pens between 25 and $103 \mathrm{~kg}$ live weight.

I. Utilization of rich lysine maize (I. N. R. A. selections in progress at Clermont-Ferrand) and / or synthetic lysine. The animals' performances were similar, but the carcasses were all the more fat as the crude protein level decreased (from i 7.5 to 15.1 p. Ioo). The rich lysine samples seemed to be of limited interest (maize percentage of the diet increased from 71.6 to 75.8 ).

2. Utilization of alcane yeast (the BP company) and fermented rapeseed oil meal. Diets containing $83.8 \mathrm{p}$. Ioo maize and $\mathbf{I} 3.2 \mathrm{p}$. Ioo yeast gave the same performance as the control diets and better carcasses, even though the crude protein percentage was reduced to r6.2 p. Ioo In the second case, the growth rate was reduced $(634 \mathrm{~g} /$ day versus $76 \mathrm{I} \mathrm{g} / \mathrm{day})$ and the feed conversion ratio was very high (3.88 versus 3.28 ).

Comparing all the diets, "Hypor " pigs exhibited poorer feed intake and lower growth rates than the Large White pigs (equivalent feed conversion ratios), their carcasses were much better, but some of them were very damaged by the transport towards the slaughterhouse.

No interaction between diets and types of pigs.

\section{ESSAI DE REMPLACEMENT DU TOURTEAU DE SOJA PAR LA FÉVEROLE DANS L'ALIMENTATION DU PORC EN CROISSANCE-FINITION}

\author{
X. HENRY et D. BOURDON \\ Station de Recherches sur l'Élevage des Porcs, \\ Centre national de Recherches zootechniques, I. N.R. A., \\ 78350 Jouy en Josas
}

\section{RÉSUMÉ}

Grâce à la qualité de ses protéines et principalement à la richesse de ces dernières en lysine $(6,5$ à $7 \mathrm{~g}$ pour $\mathrm{I} 6 \mathrm{~g} \mathrm{~d} \mathrm{~d} \mathrm{~N})$, la féverole peut constituer une source azotée de remplacement pour le tourteau de soja dans l'alimentation du Porc. Deux expériences ont été réalisées sur des porcs en croissance-finition, entre 25 et $90 \mathrm{~kg}$ de poids vif, dans le but d'étudier les possibilités de substitution totale ou partielle du tourteau de soja, par la féverole, en association avec l'orge ou 